\title{
Articles
}

\section{Bringing Community Back to Community Health Worker Studies: Community interactions, data collection, and health information flows}

Eric Ryan Obeysekare

Khanjan Mehta

Carleen Maitland
Pennsylvania State University, USA

Corresponding Author.

eric.obeysekare@gmail.com

Lehigh University, USA

krm716@lehigh.edu

Pennsylvania State University, USA

cmaitland@ist.psu.edu

Community Health Workers (CHWs) have the potential to be a great resource in the further growth of fledgling healthcare systems in developing countries. Through their position as community members, CHWs can interact with other individuals in the areas where they live and work, serving as valuable health resources by providing basic health information and referrals up the healthcare chain. However, few studies examine CHWs from a community-based perspective. This study analyzes the work and relationships of several CHWs working for the Mashavu mHealth venture in Nyeri, Kenya. Using participant observation and interviews, the workflows of these CHWs were investigated with a specific eye towards interactions between CHWs and their communities and how these interactions affect potential health data collection opportunities. This community-based perspective reveals unique insights into the workflows of the CHWs as well as how technology might be designed to support them.

Obeysekare, E., Mehta, K., Maitland, C. (2017). Bringing Community Back to Community Health Worker Studies: Community interactions, data collection, and health information flows. The Journal of Community Informatics, 13(3), 75-97.

Date submitted: 2016-10-24. Date accepted: 2017-08-21.

Copyright (C), 2017 (the author as stated). Licensed under the Creative Commons AttributionNonCommercial-ShareAlike 2.5. Available at: www.ci-journal.net/index.php/ciej/article/view/1358 


\section{Introduction}

Access to healthcare in the developing world is a pressing concern, affected by factors including location, finances, and availability of health resources (Peters et al., 2008). Among these, the most significant is an overall lack of healthcare professionals in lowresource contexts (World Health Organization, 2014). Community Health Workers (CHWs), individuals who receive limited training in healthcare (as compared with better trained nurses or doctors), are one way to address this deficit (Swider S. M., 2002). CHWs are community members with an interest in public health who work, often without pay, to promote better health within their own communities. In recent years, CHW programs have been growing, with the World Health Organization estimating in 2011 there were over 1.3 million CHWs worldwide (World Health Organization, 2011). Given the relative novelty of these programs, governments and non-governmental organizations (NGOs) are still identifying how they can best be used to improve fledgling healthcare systems in developing countries.

One potential role for CHWs is serving as data collectors. A lack of data, particularly for understanding general health trends and challenges, is an ongoing problem in developing country healthcare provision. Data collection is seen as one way to improve healthcare delivery and is an area where CHWs can be harnessed. Research on the use of information and communication technologies (ICTs) in health data collection in developing countries focuses on several areas: the use of mobile phones for healthcare and health information purposes (Trause et al., 2014; Braun, Catalani, Wimbush, \& Israelski, 2013; Kahn, Yang, \& Kahn, 2010), the deployment and evaluation of health information systems in developing countries (Odhiambo-Otieno and Odero, 2005; Kimaro and Nhampossa, 2005; Braa, Hanseth, Heywood, Mohammed, \& Shaw, 2007), and how health data from developing countries can be harnessed (Bram, WarwickClark, Obeysekare, \& Mehta, 2015). However, the impact of these efforts has been disappointing, with some considered outright failures. Understanding the reasons for these failures, and more specifically the factors that affect health data collection in these contexts, will help improve CHW programs and unlock their true potential.

To address this goal of generating a greater understanding of health data collection, our research focuses on one of the most valuable characteristics of CHWs: their status as community members, which enables them to effectively reach the people they are serving. CHWs can communicate easily with and are well-known in their communities. For example, CHWs in a study conducted in Kenya emphasized the importance of being friendly in their interactions with others, mentioning that this can aid in the sharing of important information (Trause et al.). Furthermore, CHWs' relationships with the community members they serve is a critical factor affecting their success as healthcare workers (Strachan et al., 2012). It is clear CHWs' position within their communities influences their work as healthcare providers. However, research has yet to examine this broader role, outside the context of communicating health information, despite calls for just that type of research as far back as 1984 (Nichter, 1984). Viewing CHWs as community members, not simply health workers, raises a critical question: What types of interactions take place between CHWs and their communities and how do these affect potential health data collection? 
This article addresses these questions through a case study of Mashavu, an mHealth venture focused on health information provision in Kenya. Expanding from a narrow view focused solely on health data collection to a broader picture of information flows between CHWs and community members enables a more careful analysis of how information and communication technologies might be effectively used by CHWs. In what follows, we begin with a review of the literature on CHWs, health information systems, and social capital, and then describe the methods of this study. A short introduction to Mashavu is then followed by the findings of this research. A discussion of the implications of these findings is then given. Finally, recommendations for the design of technologies to be used by CHWs are outlined. This article will be of interest to three groups, namely those working with $\mathrm{CHW}$ programs in developing countries, academics studying the role of community in the use of technology, and designers developing data collection technologies for use in low-resource contexts.

\section{Related Work}

Relevant related work for this study comes from three bodies of literature: CHW studies, Health Information System studies, and Social Capital and Trust studies. The following section will highlight important points from these bodies.

\section{CHWs}

The World Health Organization's Alma Ata Declaration in 1978 established health as a basic human right. Achieving this goal in developing countries requires the expansion of healthcare systems, many of which are experiencing a shortage of trained healthcare workers (Naicker, Plange-Rhule, Tutt, \& Eastwood, 2009). To address this deficit many countries are turning to Community Health Workers (CHWs) (Swider S. M., 2002). Community Health Workers can be described as "community members who work almost exclusively in community settings and who serve as connectors between health care consumer and providers to promote health among groups that have traditionally lacked access to adequate care" (Witmer, Seifer, Finocchio, Leslie, \& O'Neil, 1995). Literature on Community Health Workers, summarized below, consists of three general themes: general information about CHWs and their effectiveness, empowering CHWs with technology, and studies of the working networks of CHWs.

Individuals facilitating health services in their own communities is an idea that has existed for more than 50 years (Lehmann and Sanders, 2007). However, following the Alma Ata declaration, formal CHW programs began to emerge as a means of reaching this goal (Christopher, Le May, Lewin, \& Ross, 2011). A report by the World Health Organization states "CHWs can make a valuable contribution to community development and, more specifically, can improve access to and coverage of communities with basic health services" (Lehmann and Sanders, 2007).

But who are Community Health Workers? The characteristics and demographics of CHWs vary widely both within countries and between countries (Lehmann and Sanders, 2007). Some national CHW programs utilize only women while others have no gender requirements and are composed of both male and female CHWs. A study conducted in 
Kenya found the gender of CHWs did not change their effectiveness (Trause, et al.). CHWs are often of adult age (Lehmann and Sanders, 2007). However, unlike gender, age can have an effect on CHWs as they do their jobs - younger community members often are more comfortable talking to CHWs closer to their age about sensitive topics (Trause, et al.). While the education requirements for individuals wishing to become CHWs vary by country and program, most CHWs have little or no education beyond the secondary level (Lehmann and Sanders, 2007). While this does limit the level of care that CHWs can provide, it also makes the programs accessible to a large group of individuals.

Much of the literature on Community Health Workers focuses on their effectiveness as healthcare providers. Christopher et al.'s review of studies on CHWs' impact on the prevention of child mortality and morbidity in sub-Saharan Africa recommended expanded CHW programs in these regions, an effort that could have a noticeable impact on certain childhood illnesses (Christopher, Le May, Lewin, \& Ross, 2011). Another review arrived at similar results for childhood morbidity and mortality and also found CHWs can be effective in combating common illnesses (Lewin et al., 2006). Other studies look at the effectiveness of CHWs in fighting specific diseases like dysentery (Ronsmans, Bennish, \& Wierzba, 1988) or tuberculosis (Islam, Wakai, Ishikawa, Chowdhury, \& Vaughan, 2002). These studies are largely conducted by medical professionals interested in the use of CHWs to improve community health.

A segment of the literature also examines how CHWs can be empowered to be more effective with technology. Advances in information and communications technologies (ICTs) have the potential to improve healthcare systems, especially in developing countries (Chandrasekhar and Ghosh, 2001). This can be accomplished in multiple ways including the use of ICTs as an educational tool and using them to improve healthcare delivery in underserved areas. Community Health Workers who are part of telemedicine or mHealth programs can use technology to both learn more about health issues and to communicate patient health data from remote areas to those with a greater number of trained healthcare professionals (Trause et al., 2014). Data collection is a task often relegated to CHWs and is an area where technology can be applied (Braun, Catalani, Wimbush, \& Israelski, 2013). Additionally, providing CHWs with innovative technology solutions will empower them to be more effective in their work (Buehler, Ruggiero and Mehta, 2013).

Finally, research has also examined the social networks of Community Health Workers. A study by Campbell et al. (2014) focused on CHWs in Malawi. Recognizing these CHWs lacked important health information critical to their work, the research team designed a system, using mobile phones, to facilitate the flow of information. Using social network analysis techniques, they then mapped the flow of health information among the CHWs and other support organizations. Kaonga et al. (2013) used a similar approach, introducing a mobile phone system to a Ghanaian health team. After analyzing communications between members of this health team, the researchers considered the organizational structure of the team with an interest in improving it. The organizational structures of several community health worker programs and organizations supporting them have also been studied in Kenya and Ethiopia aiming to increase the effectiveness of those CHWs (Liu, Sullivan, Khan, Sachs, \& Singh, 2011). 
The common theme between these studies is healthcare work done by Community Health Workers and improving their effectiveness. A second commonality is their failure to recognize the relationships between these workers and members of the community.

\section{Health Information Systems}

Data and information flows generated by CHWs contribute to larger national health information systems. These systems and the analyses they enable aim to make more efficient use of scarce health resources. In Kenya, the Ministry of Health created the Health Information Systems Department to collect health data and use it to improve the country's healthcare system (Odhiambo-Otieno and Odero, 2005). Another study looked at the use of geographic information systems to better understand the spread of malaria across developing nations (Omumbo et al., 1998). Health information systems were also used in Kenya to understand the impact of referrals from lower levels of the healthcare system, like rural clinics, on higher levels of the system, like hospitals (Macintyre, Lochigan and Letipila, 2003). The use of technologies such as health information systems stands to benefit fledgling healthcare systems in developing countries.

mHealth or Mobile Health systems are one specific type of health information system, that employ "mobile communication technologies to revolutionize healthcare service delivery and improve beneficiary health" (Chib, 2013). A review of mHealth applications showed they can be used to spread health information over the internet, SMS, and other mobile communication platforms, as well as connect community members with healthcare professionals, collect health data, and aid in health resource distribution (Kahn, Yang and Kahn, 2010). mHealth programs are often targeted at CHWs, with successful ventures making CHWs more effective (Braun, Catalani, Wimbush and Israelski, 2013).

The characteristics of mHealth venture users (the community members receiving mHealth services) is an area that has not been widely researched. A study examining mHealth quality did examine user characteristics, including demographic variables like age, sex, and income. It also examined situational phenomena such as service cost, past experiences, and social influence, as factors that affect the perceived quality of mHealth services (Akter, D'Ambra and Ray, 2010). Other studies give basic demographic characteristics about their customers. In a review of telemedicine business models, Chen et al. examine the customer segments of several telemedicine ventures operating in developing countries, but little information is given about the demographics of customers, aside from one venture that focuses on women (Chen, Cheng and Mehta, 2013). Other mHealth programs are targeted specifically at pregnant women and women with children (Chen, Cheng, \& Mehta, 2013; Larsen-Cooper, Bancroft, Rajagopal, O'Toole and Levin, 2016). However, despite brief mentions, these studies do not provide any additional information about the users of mHealth services (for example, their motivations or behaviors). A more in-depth analysis of the customers of mHealth ventures is needed.

Implementing these health information systems, mHealth and national systems alike, is no easy task, with challenges ranging from workflows and standards to the very basic 
issue of having data to share. A case study conducted in Tanzania and Mozambique found that creating sustainable health information systems faced several challenges, including the integration of these systems into the existing workflows of healthcare workers (Kimaro and Nhampossa, 2005). A need for standards in complex health information systems in developing countries is also identified as an important challenge for systems developers (Braa, Hanseth, Heywood, Mohammed and Shaw, 2007). Additionally, collecting data to be processed in these systems is necessary before any of their frequently spoken of benefits, like improved efficiency and better resource allocation, can be achieved (Bram, Warwick-Clark, Obeysekare and Mehta, 2015).

Health Information Systems require data to be truly effective; data that could be collected by CHWs. Existing literature has, for example, examined the reliability of data collected by CHWs in Rwanda finding that while CHWs could collect reliable data, monthly reports created from these data were not of the same quality (Mitsunaga, 2014). Another study focused on the technical flow of data being collected by mHealth systems, investigating issues related to, among other concepts, data storage and security (Prasad, 2015). Data collection can also be challenging due to non-technical factors like a lack of incentives for CHWs to collect data, a lack of training about data collection, and privacy concerns (Shovlin, Ghen, Simpson, \& Mehta, 2013; DeRenzi et al., 2011). It is also important for data collection tools to fit into existing workflows. This point is touched on in (Chen K., 2011); however, their study focuses on data and technological aspects of the workflow. These challenges, as well as others, can lead to failure, either outright or from a sustainability standpoint.

\section{Social Capital and Trust}

As CHWs are embedded in their communities, their work is likely to be affected by their social capital. Perhaps the first occurrence of the term 'social capital' appeared in American literature in a 1985 translation of an earlier work of Pierre Bourdieu (Bourdieu, 1985). Bourdieu's original definition of social capital explains it as "the aggregate of the actual or potential resources which are linked to possession of a durable network of more or less institutionalized relationships of mutual acquaintance and recognition" (Bourdieu, 1985). That is to say the resources that are connected to membership in a group of which the members share some common traits. This therefore requires two things: membership in a group and some resources, tangible or intangible, that can be given to someone you know (Portes, 1998). Fukuyama, who has written extensively about both trust and social capital, calls social capital "any instance in which people cooperate for common ends on the basis of shared informal norms and values" (Fukuyama, 2002). These definitions all have two things in common: social relationships based on something in common and the benefits one gains as a result. This is the basic definition that will be used in this article.

Trust and social capital are two concepts forming the basis of many parts of human interactions. The two concepts are closely related and both play an important role in the development of a community (Fukuyama, 2002; Fukuyama, 1996; Humphery and Schmitz, 1998; Woolcock and Narayan, 2000). Because of their role in economic development, trust and social capital have important implications for researchers and 
humanitarian aid workers in developing countries. According to Fukuyama, "most developing countries actually have an abundance of social capital" (Fukuyama, 2002). For researchers of Information and Communications Technologies' impact on economic development (ICTD), these are important concepts as the introduction of technology may be able to increase both factors (Heeks, 2008).

Examining social capital and trust in the specific domain of mHealth, Akter et al. identified service quality and trust as two important factors potentially affecting the ability of an mHealth venture to continue operations (Akter, Ray, \& D'Ambra, 2012). Trust is a key factor that customers consider when deciding whether to continue use of an mHealth service. Another similar study looking at mHealth service quality identified interpersonal interaction quality and satisfaction as components of mHealth quality (Akter, D'Ambra, \& Ray, 2010). If CHWs are to work with mHealth programs, trust and social capital will be essential for their success.

Relationship maintenance, an integral component of social capital, is also likely to have implications for CHWs. Given that social capital is predicated on a relationship between two parties, maintenance of that relationship is vital. Trust and relationship maintenance are especially important in regard to service relationships - those relationships where one individual receives a service from another (Aurier and N'Goala, 2010). A study of banking relationships in Bangladesh found that customer interaction is key to maintaining ties (Fatima and Razzaque, 2013). Another study looking at banking in Ghana found that relationship maintenance and maintaining a trustful relationship with customers increased their satisfaction (Narteh and Kuada, 2014). Trust was also found to be central to selecting a healthcare service in Brazil (Fregidou-Malama and Hyder, 2015). Together, these studies demonstrate that maintaining a strong relationship between service provider and customer promotes satisfaction and loyalty.

\section{Research Questions}

In summary, CHWs' play a critical role in healthcare and health information systems. The data they collect can serve as the basis for effective national health systems, and technologies have been developed to help improve these systems' information flows. However, their successful adoption needs to consider workflows as well as the relationships, shaped by social capital and trust, of the CHWs both with one another and with other members of their communities.

Despite their name, to date little research has been conducted about Community Health Workers, community, and interactions between the two. For mHealth ventures and other attempts to design and deploy health information systems with CHWs, this is especially important. CHW-community interactions are central to the success of such systems and factors such as trust and social capital must be investigated. Therefore, by taking a community informatics perspective, this article will answer the following research questions:

1. How do CHWs' interactions with the members of their communities affect information flows?

2. How do community ties and social capital affect the work of CHWs? 
3. How do social factors, related to community, affect data collection and technology use by CHWs?

\section{Methods}

This article presents a case study of Mashavu, an mHealth venture operating in Nyeri, Kenya. Nyeri is a town located in the Central Highlands of Kenya. It has a daytime population of around 300,000 and a nighttime population of about 100,000; this difference is caused by the amount of regional business and social affairs that take place in Nyeri due to it being the seat of the eponymous Kenyan county. Mashavu employs CHWs to provide basic health information to community members for a small fee. Most CHWs in Kenya operate as volunteers; Mashavu gives CHWs the opportunity to earn some money while working. The venture exists as a larger action research project of the authors' university's Humanitarian Engineering and Social Entrepreneurship (HESE) program. Researchers work with Mashavu and the venture's CHWs to develop low-cost, sustainable solutions to healthcare issues seen in Nyeri.

This study was conducted during three weeks of ethnographic fieldwork conducted in Nyeri, Kenya in May 2014. The intent of this fieldwork was to evaluate a customdesigned data collection device that would allow the CHWs to collect digital health data (details of the design of this device can be found in Wenner, Marino, Obeysekare, \& Mehta, 2014). During this time, data were collected using participant observation, semistructured interviews, and unstructured interviews. Six 3 to 4-hour observation sessions were conducted with three Mashavu CHWs. Along with the three CHWs, these observations included several hundred community members, some of whom also answered questions from the researchers.

Observation in this study can be considered participant observation as the researchers also took part in the CHWs' work while in the community (Patton, 2002). Participation included assisting the CHWs with measurements as they requested, as well as short conversations with community members while the CHWs worked with them. Participant observation is a technique sometimes used in CHW studies (Harvey et al., 2008; Kobetz et al., 2009) and its use has even been advocated for studies of community health and CHW programs (Nichter, 1984). Throughout the participant observation sessions, unstructured or conversational interviews (Patton, 2002) were conducted with the CHWs and community members to clarify phenomena seen during observations. After several observation sessions, interviews were scheduled with each of the CHWs to collect more information about their work and place in the community. These interviews were semi-structured interviews, another common technique in CHW research (Stekelenburg, Kyanamina, \& Wolfers, 2003; Cherrington et al., 2008), designed to discuss certain topics with the CHWs but in an open format that allowed them to express their opinions on a variety of different subjects.

As the health data collection device needed to be directly integrated into the Mashavu CHWs' workflows, observation began without use of the device in order to better understand how the CHWs normally conduct their work for Mashavu. This time also allowed for a rapport to be established between the CHWs and researchers before a new device was introduced into their workflow. Following multiple sessions of observation 
without the device, a meeting with the CHWs was conducted to demonstrate the health data collection device. Observations then continued with the CHWs each taking a turn using the device during their workdays. As they used the device, feedback was collected from both the CHWs and the community members with whom they were conversing. Results and findings of observations conducted during fieldwork are presented in this article.

\section{Mashavu Case Study}

Mashavu is a social entrepreneurial mHealth venture that was launched in 2011 by the Pennsylvania State University's Humanitarian Engineering and Social Entrepreneurship Program. The Mashavu venture has several goals:

- to provide pre-primary healthcare to community members

- to create a source of income for CHWs working with Mashavu

- to increase community member's knowledge of basic health information

- to create profits that can be re-invested into the growth and improvement of Mashavu

Mashavu began its life as a telemedicine system designed to connect community members with professional nurses. In its first iteration, Mashavu utilized stationary kiosks where individuals could come to receive health consultations (Holmes, Suffian, Lackey, \& Mehta, 2014). CHWs working at these kiosks would collect health information about each patient that would then be transmitted via the internet to medical professionals who could make a preliminary diagnosis. Subsequent models moved to make the CHWs more mobile by storing data on a mobile computing device until a connection could be established to send this data on to the nurses (Qin, Dzombak, Amin, \& Mehta, 2013). Efforts to improve Mashavu resulted in further evolutions of the venture's service and business model. These changes were aimed at maximizing the potential income that could be earned by Mashavu CHWs while also making Mashavu itself financially sustainable.

In its current form, Mashavu accomplishes its four goals by offering a service called "Know Your Numbers". Mashavu CHWs are given basic medical equipment including a scale, tape measure, and blood pressure device, and are trained in their use. They then travel throughout Nyeri and the surrounding communities and for a small fee provide interested individuals with their height, weight, blood pressure, pulse rate, and body mass index (BMI). This service costs 30 Kenyan Shillings and is priced to be the same price as a bottle of Coca-Cola. In addition to the medical information, these interactions allow CHWs to communicate medical advice about improving aspects of their health related to the provided information. During fieldwork in Nyeri, the authors had the opportunity to extensively observe the CHWs as they provided the Know Your Numbers service.

At the time of data collection, there were three CHWs who were in good standing with Mashavu. That is to say that they were consistently working and active within the organization. The three CHWs are all older women, the youngest roughly 45 years old 
and the oldest roughly 60 years old. They all grew up in the Nyeri area and speak the Kikuyu language that is widely used in the area. Although they speak Kikuyu most often in their day-to-day lives, their English is quite good, and the researchers were able to easily communicate with all three CHWs in English. During their day-to-day work, the three CHWs each focus on communities throughout the greater Nyeri region, communities that they themselves are a part of.

\section{Findings and Discussion}

Results of this study can be grouped into four categories: the place of CHWs in their communities, interactions and health information flows of CHWs and community members, how social capital and health information flows affect CHW entrepreneurship, and the data collection processes that the CHWs utilize.

\section{Community Health Workers and Their Place in the Community}

In this article, three different CHWs were interviewed and observed. Literature on Community Health Workers notes that CHWs are often women of adult age with little education (Lehmann and Sanders, 2007). All three Community Health Workers fit these characteristics. The literature also notes that gender does not have a large effect on the work of CHWs (Trause et al.). However, beyond these largely demographic qualities of CHWs, the literature does not contain much information about different types of CHWs. This study expands on that literature by identifying some characteristics of these particular CHWs.

For example, some differences were noted between the working, social, and entrepreneurial attitudes of the three CHWs. One of the CHWs was noted to be the shyest member of the group upon first meeting her, something that was confirmed during subsequent observations and interviews. Although she was quite active in one neighboring town, she was content with relatively fewer customers than the others. In addition, all her customers are individuals she met simply by offering the Mashavu Know Your Numbers service. This CHW also conducts no other economic activities in the geographic areas analyzed, instead preferring to spend her time at home. Rather than a critique, this is merely an observation of differences in her working and social styles as compared to the others discussed below. Further, it appears she has received the least secondary benefits from the social capital gained as a result of working for Mashavu. Nonetheless, she enjoys working for Mashavu and is still having a positive impact on her community through her work as a CHW.

The other two CHWs were observed to be more social. While walking around town with these two CHWs, it was clear they had many contacts in the community. They would often stop to talk to other individuals they knew. These conversations would often involve a short explanation of what they were doing with Mashavu and would sometimes result in a Know Your Numbers consultation being performed, if requested. Both of these CHWs have a mix of customers; some met through Mashavu as well as those met through other means. Also, these customers might be one-off or repeat clients. One of the CHWs knew 6 out of 20 of her repeat customers prior to working with 
Mashavu. The other met the majority of her repeat customers (27 of 46) outside of her work with Mashavu. She was able to effectively use her existing social networks to find new customers, provide them with the Know Your Numbers service, and turn them into long-term repeat customers. Also, both of these CHWs engage in many different entrepreneurial activities outside of Mashavu. The social capital built through Mashavu has been valuable as they conduct business activities with individuals met through Mashavu work.

A finding of this research is the value these reciprocal ties generate for health services, the clients and the CHW. Whereas the majority of existing literature about CHWs concentrates on their role in health interventions (e.g. (Christopher, Le May, Lewin, \& Ross, 2011; Lewin et al., 2006; Ronsmans, Bennish, \& Wierzba, 1988; Islam, Wakai, Ishikawa, Chowdhury, \& Vaughan, 2002), our research suggests a broader view of relations provides a more complete understanding of the context of healthcare work.

Hence, it is important to recognize that CHWs are first and foremost members of their community. This point was identified by several CHW experts as important - we need to better understand the CHWs themselves in order to create better programs for them (Strachan et al., 2012). This article offers some data in response to this prompt. In practice CHWs play complex roles within their communities that involve a variety of other community organizations (church and school groups, for example) as well as personal businesses (like raising animals or running a small motorcycle taxi business). Better understanding of the role that Community Health Workers play in their communities, beyond health facilitation and other health services they conduct, can lead to better interventions by international development organizations and may bring forth projects intended to benefit the CHWs themselves.

\section{CHW-Community Member Interactions and Information Flows}

The three Mashavu CHWs were observed to have two different types of customers: repeat and transient customers. Repeat customers received the Know Your Numbers service from the CHWs on a regular basis, whether once a week, once a month, or somewhere in between. The CHWs have developed relationships with these individuals and make sure to visit them regularly. Transient customers, on the other hand, are individuals who pay the CHWs for the Know Your Numbers service, but without any regularity. Understanding the different ways that individuals seek and consume health information can contribute to health information theories as well as CHW program implementation. Additionally, by understanding heterogeneity of health information needs and interests, it is possible to design programs that specifically target each type of individual.

In this case, individual differences in information needs and interests were observed as four types of information flows between the Mashavu CHWs and their customers: general health knowledge, personal health information, paper receipts, and data collection by the CHWs. General health knowledge refers to general information the CHWs communicate to individuals about health (for example: eating healthily, keeping things clean, etc.). Personal health information refers to the Know Your Numbers service. Paper receipts are given to some (but not all) individuals as a record of this 
information and data collection occurs when the CHWs keep track of this information for their own and Mashavu's records. Figure 1, below, shows a model of the CHWs' interactions with the two types of customers. All four types of information flows occur between CHWs and repeat customers. Transient customers, however, only receive personal health information and general health knowledge. The "Group of transient customers" block represents individuals who may be present during a Mashavu interaction but do not directly receive the Know Your Numbers service themselves. These individuals still receive general health knowledge from the CHWs by overhearing and participating in discussions between the CHWs and the paying customers.

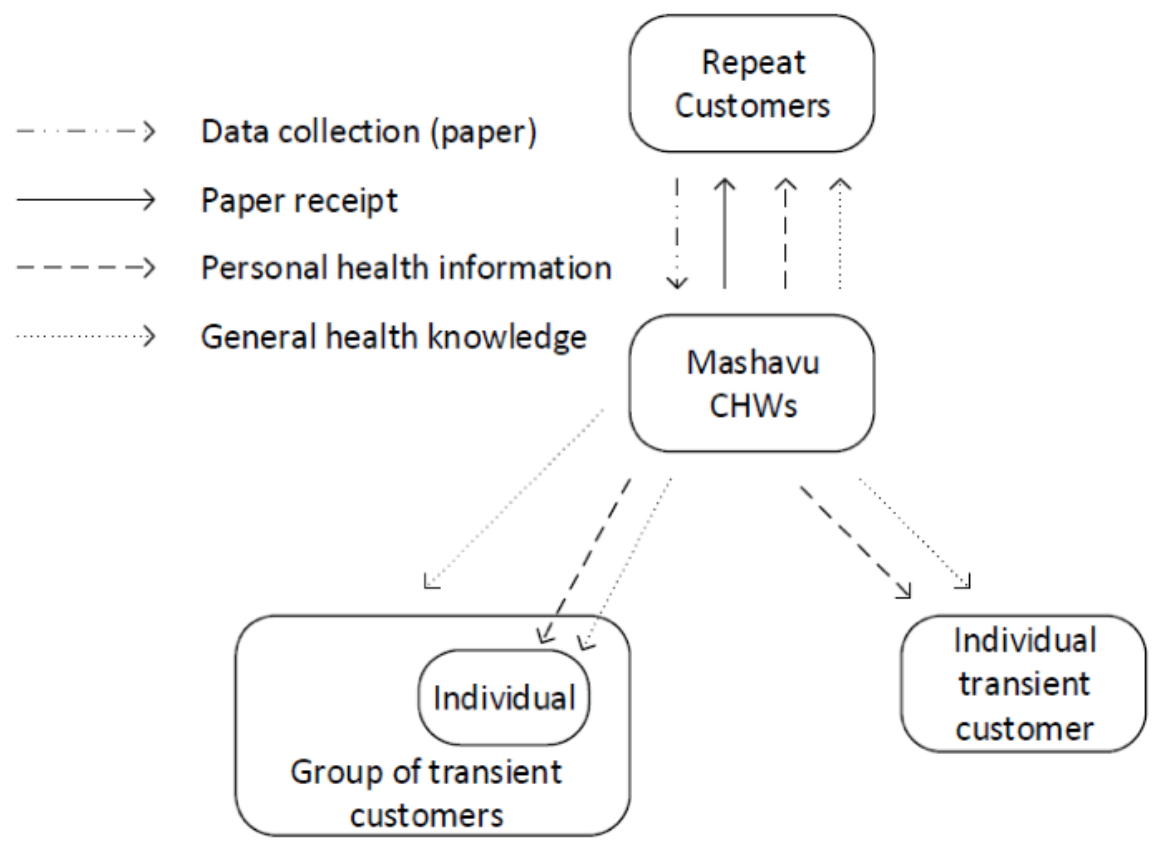

Figure 1: Customer types and information flows

While accompanying the CHWs during their work, several repeat customers were visited. Most of these visits occurred at the customers' places of work, which the CHWs would occasionally go out of their way to visit. The interactions between the CHWs and the repeat customers were usually one-on-one interactions and involved both measurements and a discussion of that individual's health trends (personal health information and general health knowledge). Repeat customers almost always get the full Know Your Numbers service including height, weight, BMI, and blood pressure and receive a paper receipt with a record of their numbers. The CHWs keep carbon copies of these receipts that are intended to be used in broader health data collection efforts. The repeat customers seen during fieldwork were interested in losing weight and decreasing blood pressure. Some just wanted to be healthier while others were concerned about diabetes, a disease that is becoming more widespread in the area where Mashavu operates. The overall motivations of repeat customers can be considered to be health-related - they have a definite interest in their own personal health.

The second type of customer are referred to as transient customers. Transient customers are seen by the CHWs while they are walking around the towns and villages where they work. During their work, the CHWs spend most of their time in the outdoor markets 
and other public areas where there are large numbers of individuals gathered during the day. These individuals might be working in the market (for example, a group of women who were each selling vegetables in the market were seen) or spending time with their friends. When a CHW interacts with a transient customer, it is often in a group of five or more individuals. These group interactions are valuable for the CHWs because they enable communication of personal health information and general health knowledge to multiple individuals simultaneously. Transient customers rarely receive paper receipts and may also choose to get a partial Know Your Numbers service. This means that they will pay less and in turn only receive their height, weight, and BMI or alternatively, just their blood pressure and pulse rate. Offering these partial services allows the CHWs to have more business as transient customers may be unwilling to pay the full price or uninterested in receiving the full service.

While repeat customers were mostly motivated by a desire to be healthy, transient customers seemed to have different motivations. Many of the groups of transient customers observed appeared to be treating the Know Your Numbers service as a form of entertainment. Some interactions would turn into a competition amongst the group interacting with the CHW. This could involve individuals competing to see who weighed the most or who was the tallest. Competitions often occurred when there was a group of young men with whom the CHWs were conversing. In such situations there might be one individual who has some money he or she is willing to spend. After getting his or her own health information, this individual would then encourage others to do the same and may then end up paying for the others to get the service.

Differences in health information seeking behaviors in developing countries have yet to be systematically researched and reported in the literature. While some studies do mention basic demographic characteristics of customers, including those targeted at pregnant women and women with children (Chen, Cheng, \& Mehta, 2013; LarsenCooper, Bancroft, Rajagopal, O'Toole, \& Levin, 2016) and Akter et al.'s study that identifies age and sex as user characteristics that can affect the success of mHealth ventures (Akter, D'Ambra, \& Ray, 2010), no studies have taken an in-depth look at how customer behavior might affect mHealth. Findings of this study suggest customers of the Mashavu mHealth service are motivated both by health concerns and entertainment. Further research is required to systematically investigate these differences and identify whether these motivations are consistent across a variety of developing country mHealth ventures.

\section{Social Capital, Health Information, and Entrepreneurship}

The three CHWs also used increased social capital, grown through their Mashavu work, to conduct new types of entrepreneurial activities, providing additional sources of income. In Kenya, as well as many other developing countries, Community Health Workers are unpaid volunteers. This results in many CHWs needing to find other sources of income to support themselves and their families. This is one of the reasons Mashavu and the Know Your Numbers service was first created - to provide a source of income for some CHWs. During data collection, the CHWs were asked about other business activities they conduct in the various towns and villages where they work. 
There are a wide range of these activities including raising animals, sharing resources, saving money, employing a motorcycle taxi driver, and providing other health services like a diabetes support group. The individuals with whom they conduct these businesses are similar to their group of customers (in fact some are their Mashavu customers) they are a varied group of individuals spread across several communities in the area.

Unlike more arms-length business relationships in the West, developing country business relationships tend to be more personal, tied in with existing social relationships (Fukuyama, 2002). Consequently, social capital is extremely important. During interviews, the CHWs were asked about various relationships they have with other individuals in the community and how they have changed. Based on their recollections, network diagrams were constructed showing the CHWs' various types of connections. These networks suggest growth occurred - the CHWs expanded their networks by adding individuals met through Mashavu. Figure 2 below shows an example of this growth. The network diagram on the left shows the three CHWs' (black circles) networks before they joined Mashavu, while the right diagram shows the growth in their networks that occurred due to Mashavu. This growth occurred in a variety of different types of relationships. Of the three CHWs interviewed, two of them participated in a number of different entrepreneurial activities within their communities. One of them used contacts met through Mashavu work to increase her network of business partners from 10 individuals to 15 , while the other increased her network of business partners from 16 to 25 individuals. This suggests their work as CHWs enabled them to increase their own personal social capital and then use it to enter new business opportunities. Like many individuals in the developing world, these CHWs were engaged in a variety of different economic activities (rather than having one primary source of income). Being part of Mashavu allowed the CHWs to amplify an existing behavior. This finding is line with extent research that suggests social capital can be used to increase economic development (Fukuyama, 2002).

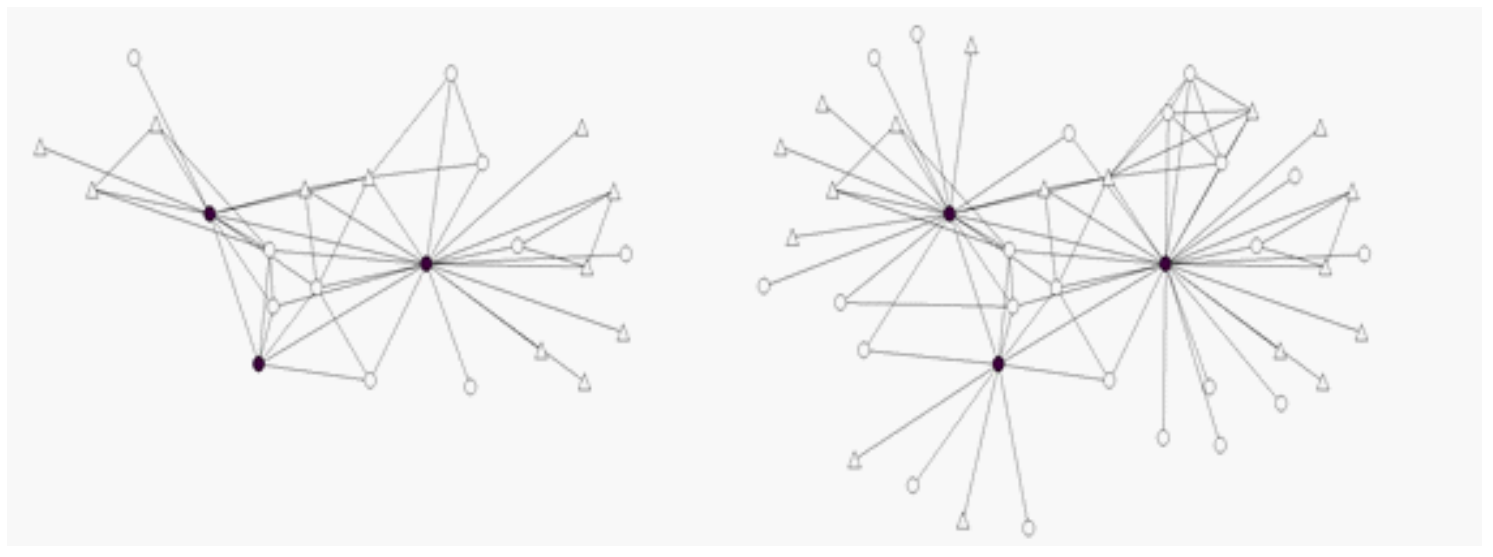

Figure 2: Network diagrams showing Mashavu CHW social capital growth. Left shows connections made before Mashavu, right shows additional connections made through Mashavu. Circles represent women, while triangles represent men; CHWs are filled-in circles.

Despite the potential positive economic impact, the secondary benefit of CHWs growing personal social capital while conducting their normal $\mathrm{CHW}$ work is rarely discussed. Future research should investigate this potential benefit as a motivating 
factor for CHW recruitment and operations. Furthermore, to date, studies of CHWs' networks are limited to health information networks within the healthcare system (Campbell et al., 2014; Kaonga et al., 2013) or organizational structures in which CHWs are embedded (Liu, Sullivan, Khan, Sachs, \& Singh, 2011). These studies each focus on only one specific type of CHWs' relationships. However, results shown here suggest CHWs' networks are much more complex than previously portrayed, involving many different types of relationships. A holistic view of these relationships and their resulting social capital is needed to truly understand the networks of CHWs and how they might be used to promote their work and affect development. Specifically, future research should systematically investigate whether and how CHWs can use increased social capital, operationalized in this study as additional relationships established with diverse individuals, to spread health information and undertake entrepreneurial activities that provide them with a source of income. Such studies would contribute to the existing literature about CHWs that until now only concentrated on formal health networks and organizational structures.

\section{CHWs' Data Collection Processes}

Before the field work reported here, past Mashavu health data collection efforts attempted to introduce digital technologies ranging from laptops to smart phones to basic feature phones. Despite these multiple attempts, the Mashavu CHWs never bought into the idea of digital data collection. To remedy this, paper receipt books were created. These books contain removable receipts with spaces to record the information from the Know Your Numbers service. Using carbon paper, the CHWs fill out the removable receipts while also leaving a copy of the receipt in the book. If these data needed to be analyzed or transferred, they could be digitized by hand into a database. However, this is not currently being done as the Mashavu organization lacks the resources. Consequently, for the purpose of understanding community health trends, the data currently being collected is largely wasted.

Furthermore, these paper receipts are not given out to every individual who receives the Know Your Numbers service. Rather, the receipts are mainly given to repeat customers. For example, during one day of observation, a CHW saw approximately 100 customers yet only distributed about six receipts. When asked why they were not giving receipts to everyone, the CHW replied that the majority of people they would see during the day were not interested in getting a receipt of their health information. Further observation revealed that the transient customers (who make up the majority of individuals a CHW sees in one day) were the ones who did not want receipts. Some of the customers were asked if the reason that they did not want receipts was because their personal information was being recorded. However, they replied that this was not the case and they just had no need for the receipts. Because the customers are not interested in getting receipts, their data never gets recorded, significantly weakening the potential of the Mashavu CHWs to serve as data collectors at this time.

In addition to the lack of interest, there are several other factors which affect data collection from repeat customers, those more likely to want receipts. These factors can be summarized by saying that the technological solutions tried by Mashavu do not fit 
into the workflows of CHWs (something that can cause data collection to fail (Chen K. , 2011)). First, the large groups that often accompany a CHW-customer interaction require a great deal of attention from the CHW. When talking to these groups, there will be multiple people asking questions of the $\mathrm{CHW}$ at the same time. Then, when the time comes for measurement, the $\mathrm{CHW}$ may be measuring multiple customers simultaneously. While taking the height and weight of the first customer in the group, the $\mathrm{CHW}$ may give the blood pressure to another customer to begin their measurements. Before this second customer's blood pressure is measured, the CHW may have taken the height and weight of one or two additional other people. This method allows the CHWs to quickly provide service to larger groups. However, it also causes most measurements to occur in an asynchronous fashion making individual record collection quite challenging. The CHW would have to keep track of multiple customers' records switching back and forth as each measurement is taken. This would be challenging when using paper receipts and would require specialized technology designed to solve this problem for digital data collection.

Additionally, an operational principle of Mashavu requires the CHWs to work in a mobile fashion and travel to different towns and villages around Nyeri. While in these towns, they spend their time walking around and talking to as many individuals as possible, providing information to those who desire the Know Your Numbers service. In previous iterations of the Mashavu business model, the CHWs worked at stationary kiosks providing medical services. The more mobile business model currently being used was found to be more productive and allows the CHWs to reach more community members. However this mobility also has some negative consequences related to data collection. The CHWs must carry everything they need to work with them. This currently includes a weighing scale, tape measure, blood pressure cuff, receipt book, and some other documents that can be used to help communicate health information. Several of the CHWs also carry blood glucose meters to provide an additional service to some of their customers. Any device used to aid in digital data collection would have to be added to this set of objects. The CHWs must also conduct almost all their work on their feet in the middle of the market (or other public area). This means there is rarely anywhere to put the numerous devices while they are being used and the CHWs must hold them (or move the devices back and forth from their bags). Juggling an additional data collection device, like a smartphone, could therefore be undesirable for the CHWs.

Data collection is an important organizational goal of Mashavu. Health data can be used to improve the healthcare systems in developing countries like Kenya (Macintyre, Lochigan, \& Letipila, 2003). Unfortunately, past Mashavu data collection efforts involving technological solutions have largely failed. In the case of Mashavu, social factors had a major impact on data collection and technology use, ultimately leading technology-based data collection solutions to fail. Findings of this research expand on challenges to mHealth data collection like those listed in Shovlin, Ghen, Simpson, and Mehta (2013) and DeRenzi et al. (2011). Shovlin et al. define four categories of challenges to the collection of digital health data in developing countries: contextual, business, communication and coordination, and technological (Shovlin, Ghen, Simpson, \& Mehta, 2013). 
As shown in Table 1, the findings of this research as well as findings of mHealth data collection challenges mentioned by DeRenzi et al. (DeRenzi, et al., 2011), were grouped into four categories: contextual challenges, business-related challenges, communication and coordination challenges, and technological challenges. This study suggests the addition of a fifth category: social factors, which was not included in existing literature. These additional social factors challenges were observed through extended time spent with the Mashavu CHWs and the resulting in-depth comprehension of their workflows. Understanding the reasons for the failure of technology will allow researchers and designers to create better solutions that may work in the future.

Table 1: Challenges to mHealth Data Collection

\begin{tabular}{|c|c|c|c|}
\hline & Shovlin et al. & DeRenzi et al. & $\begin{array}{l}\text { Findings of this } \\
\text { study }\end{array}$ \\
\hline Contextual & $\begin{array}{ll}\text { 1. } & \text { Infrastructure } \\
& \text { Limitations } \\
\text { 2. } & \text { Transportation and } \\
& \text { Geography } \\
\text { 3. } & \text { Security } \\
\text { 4. } & \text { Privacy } \\
\text { 5. } & \text { Regulations } \\
\text { 6. } & \text { Lack of Expertise } \\
\text { 7. } & \text { Unique Patient } \\
& \text { Identifiers }\end{array}$ & 1. Privacy concerns & $\begin{array}{l}\text { 1. Mobility - } \\
\text { juggling multiple } \\
\text { devices }\end{array}$ \\
\hline Business & $\begin{array}{ll}\text { 1. } & \text { Employee Turnover } \\
\text { 2. } & \text { Mismatched } \\
\text { Incentives } \\
\text { 3. } \\
\text { 4. } & \text { Startup Costs } \\
\text { 4calability }\end{array}$ & $\begin{array}{l}\text { 1. Complexity in } \\
\text { deploying } \\
\text { workflow } \\
\text { management }\end{array}$ & \\
\hline $\begin{array}{l}\text { Communication } \\
\text { and } \\
\text { Coordination }\end{array}$ & $\begin{array}{ll}\text { 1. } & \text { Status Quo } \\
\text { 2. } & \text { Standardized } \\
& \text { Language } \\
\text { 3. } & \text { Training } \\
\text { 4. } & \text { Assumptions of } \\
& \text { Inaccuracies }\end{array}$ & $\begin{array}{l}\text { 1. General } \\
\text { communication and } \\
\text { coordination } \\
\text { challenges }\end{array}$ & $\begin{array}{l}\text { 1. Lack of } \\
\text { consistency with } \\
\text { paper receipts and } \\
\text { data collection in } \\
\text { general }\end{array}$ \\
\hline Technological & $\begin{array}{ll}\text { 1. } & \text { Backup and } \\
\text { Management } \\
\text { 2. } & \text { Accuracy } \\
\text { 3. } & \text { Equipment } \\
& \text { Reliability and } \\
& \text { Theft } \\
\text { 4. } & \text { Equipment Misuse }\end{array}$ & $\begin{array}{l}\text { 1. } \begin{array}{l}\text { Loss or theft of } \\
\text { mobile devices }\end{array} \\
\text { 2. Data exchange and } \\
\text { interoperability } \\
\text { 3. Poor or absent } \\
\text { connectivity } \\
\text { 4. Difficulties keeping } \\
\text { batteries charged }\end{array}$ & 1. Fear of theft \\
\hline
\end{tabular}




\begin{tabular}{|l|l|l|}
\hline Social Factors & & $\begin{array}{l}\text { 1. } \begin{array}{l}\text { Social interaction } \\
\text { deterrent } \\
\text { Certain } \\
\text { customers do not } \\
\text { want receipts }\end{array} \\
\end{array}$
\end{tabular}

While many researchers have looked into and recommended the use of mobile phones as data collection devices (Braun, Catalani, Wimbush, \& Israelski, 2013; Kahn, Yang, \& Kahn, 2010; DeRenzi et al., 2011), this was determined to be a poor fit for the Mashavu CHWs due to their need to engage in conversation with customers, which is a type of relationships maintenance seen as important by both parties. Existing literature about relationship maintenance appears to be largely focused on banking (Fatima and Razzaque, 2013; Narteh and Kuada, 2014) and other types of service relationships (Aurier and N'Goala, 2010). However, one study did look at the role of trust and relationships in selecting a healthcare service in Brazil (Fregidou-Malama and Hyder, 2015). Findings of this research expand on those results and show that relationship maintenance is also important for CHWs working with mHealth programs. The in-depth observations about the nature of workflows and interactions reported here shed further light on the failure of mobile phones as a data collection tool for Mashavu (for more details see (Shovlin, Ghen, Simpson, \& Mehta, 2013) and (Wenner, Marino, Obeysekare, \& Mehta, 2014)). As mobile technology develops further, and more techsavvy individuals become CHWs, this may change but at the current time the mobile phones proved to be more of an annoying distraction than helpful tools. Fear of theft, something mentioned as a challenge to mHealth data collection (DeRenzi et al., 2011) was also a concern of the Mashavu CHWs.

\section{Recommendations for Design}

The research reported here suggests several areas for improvement in health information flows and digital data capture and analysis. First, design implications for data capture by CHWs with the goals of central storage and analysis are discussed. This is followed by design recommendations for enabling repeat customers to add to their data stores and potentially provide automated analyses of their data. Finally, design recommendations related to the many, varied types of relationships that the CHWs engage in are given.

Given the challenges facing data collection mentioned here, a data collection device would need to be able to handle the multiple individuals that the Mashavu CHWs often interact with. This could be done using a voice recognition system that is able to distinguish between the multiple individuals who are part of a typical Mashavu health facilitation interaction. Using this type of technology would also require software that is able to understand the language spoken where CHWs are working (in the case of the Mashavu CHWs this is Kikuyu). The device would also need to analyze the content of 
the conversation into separate reports for each individual that could then be relayed to them by the $\mathrm{CHW}$, printed out as a paper receipt, or sent electronically to the individual.

The second challenge that must be addressed is matching health records with the same individual if they receive multiple consultations. This is especially important for repeat customers so that they can track their health information over time. Voice recognition could be used to assist in customer identification along with biometric technologies such as fingerprint readers or facial detection systems. This type of device would also need to be portable and potentially hands-free to facilitate the mobile manner in which the Mashavu CHWs work. The system should ensure data are sharable with customers, potentially transferring to a mobile application that provides visual results, like many mHealth applications used today.

The number of varied relationships and entrepreneurial activities of CHWs were shown to have important implications for their work. Designing technology to help the CHWs manage these relationships could be very beneficial. Such a system might keep track of the CHWs' other activities and groups. Then, when a CHW is providing the Know Your Numbers service to an individual with whom they have additional relationships, the system could also show them information about these other activities. This type of device, targeting the ease with which individuals manage multiple complex relationships, would have broad applicability. It would likely be useful not only to the CHWs, but also many others around the world engaging in 'gig economy' or other informal work. This would not be just a specialized health information tool, as was discussed in the other design recommendations, but a more general relationship information management platform. Understanding other instances of this type of work in developing countries could provide further design recommendations and could also consider privacy, security, and other issues.

While there are many technical challenges associated with creating these devices, the technologies mentioned here are currently being developing by industry members and these technologies are slowly trickling down to consumers. Harnessing these new innovations for use in developing countries will be a powerful tool for development organizations in the near future.

\section{Conclusion}

Community Health Workers are first and foremost members of the communities where they live and work. Their status in the community enables their work. In the case of the Mashavu CHWs, social connections in the community were harnessed and augmented into repeat customer relationships with an emphasis on health information. CHWs can also use their social status as health professionals to influence their relationships with individuals in the community who they do not know. These transient customer relationships may not have the longevity of repeat customer relationships but still involve the transfer of health information. Each of these different types of relationships involve different information flows including personal health information, general health knowledge, receipts reflecting this information, and data collection (see Figure 1 above). In addition to relationships formed around Mashavu work and health information, the CHWs also engage in many entrepreneurial relationships. These 
entrepreneurial ventures can be based on prior existing relationships but can also be the result of Mashavu interactions and health information relationships. The nature of community in this context also influences the CHWs' workflows. To see more of their communities, the CHWs operate in a mobile fashion and must carry all their supplies. Interactions between CHWs and community members are communal, group interactions. While the CHWs can easily manage these types of interactions, creating appropriate mobile technology solutions that can enable data collection is much more challenging.

This research begins to fill a gap in the literature around community-focused CHW studies. By looking at the ways community affects the work of CHWs, and also how they use technology, we can better understand CHW programs, their effectiveness, and how to best enable them with technology. Future research could build upon the results of this study by investigating CHWs in other developing countries and understanding the types of customers, community-influenced interactions, and information flows that exist. Armed with this knowledge, designers can begin to create devices focused on the low-resource contexts of developing countries and that can address the unique workflows that exist in those settings.

\section{References}

Akter, S., D'Ambra, J., \& Ray, P. (2010). User perceived service quality of m-Health services in developing countries. 18th European Conferenece on Information Systems. Pretoria, South Africa.

Akter, S., Ray, P., \& D'Ambra, J. (2012). Continuance of mHealth services at the bottom of the pyramid: the roles of service quality and trust. Electronic Markets, 23(1), 29-47.

Aurier, P., \& N'Goala, G. (2010). The differing and mediating roles of trust and relationship commitment in service relationship maintenance and development. Journal of the Acadmey of Marketing Science, 38(3), 303-325.

Bourdieu, P. (1985). The Forms of Capital.

Braa, J., Hanseth, O., Heywood, A. B., Mohammed, W., \& Shaw, V. (2007). Developing Health Information Systems in Developing Countries: The Flexible Standards Strategy. MIS Quarterly, 31(2), 381-402.

Bram, J. T., Warwick-Clark, B., Obeysekare, E., \& Mehta, K. (2015). Utilization and Monetization of Healthcare Data in Developing Countries . Big Data, 3(2), 59-66.

Braun, R., Catalani, C., Wimbush, J., \& Israelski, D. (2013). Community Health Workers and Mobile Technology: A Systematic Review of the Literature. PLoS ONE, 8(6).

Buehler, B., Ruggiero, R., \& Mehta, K. (2013). Empowering Community Health Workers with Technology Solutions. IEEE Technology and Society Magazine, 32(1), 44-52.

Campbell, N., Schiffer, E., Buxbaum, A., McLean, E., Perry, C., \& Sullivan, T. M. (2014). Taking knowledge for health the extra mile: participatory evaluation of a mobile phone intervention for community health workers in Malawi. Global Health: Science and Practice, 2(1), 23-34.

Chandrasekhar, C. P., \& Ghosh, J. (2001). Information and communication technologies and health in low income countries: the potential and the constraints. Bulletin of the World Health Organization, 79(9), 850-855.

Chen, K. (2011). Data-driven Techniques for Improving Data Collection in Low-resource Environments. 
Chen, S., Cheng, A., \& Mehta, K. (2013). A Review of Telemedicine Business Models. Telemedicine and e-Health, 19(4), 287-297.

Cherrington, A., Ayala, G. X., Amick, H., Scarinci, I., Allison, J., \& Corbie-Smith, G. (2008). Applying the Community Health Worker Model to Disease Managment: Using Mixed Methods to Assess Implementation and Effectiveness. Journal of Health Care for the Poor and Underserved, 19(4), 1044-1059.

Chib, A. (2013). The promise and peril of mHealth in developing countries. Mobile Media and Communication, 1(1), 69-75.

Christopher, J. B., Le May, A., Lewin, S., \& Ross, D. A. (2011). Thirty years after Alma-Ata: a systematic review of the impact of community health workers delivering curative interventions against malaria, pneumonia, and diarrhoea on child mortality and morbidity in sub-Saharan Africa. Human Resources for Health, 9(27).

DeRenzi, B., Borriello, G., Jackson, J., Kumar, V. S., Parikh, T. S., Virk, P., \& Lesh, N. (2011). Mobile Phone Tools for Field-Based Health care Workers Low-Income Countries. Mount Sinai Journal of Medicine, 78, 406-418.

Fatima, J. K., \& Razzaque, M. A. (2013). Roles of customer involvement in rapport and satisfaction. Asia Pacific Journal of Marketing and Logistics, 25(3), 452-471.

Fregidou-Malama, M., \& Hyder, A. S. (2015). Impact of culture on marketing of health services - Elekta in Brazil. International Business Review, 24(3), 530-540.

Fukuyama, F. (1996). Trust: Human Nature and the Reconstitution of Social Order. Simon and Schuster.

Fukuyama, F. (2002). Social Capital and Development: The Coming Agenda. SAIS Review, $22(1), 22-37$.

Harvey, S. A., Jennings, L., Chinyama, M., Masaninga, F., Mulholland, K., \& Bell, D. R. (2008). Improving community health worker use of malaria rapid diagnostic tests in Zambia: package instructions, job aid and job aid-plus-training. Malaria Journal, 7(1).

Heeks, R. (2008). ICT4D 2.0 : The Next Phase of Applying ICT for International Development. Computer, 41(6), 26 - 33.

Holmes, K., Suffian, S., Lackey, J. D., \& Mehta, K. (2014). Pilot results of a telemedicine social franchise in rural Kenya: Evidence of sustainable livelihood creation. Procedia Engineering, 78, 200-207.

Humphery, J., \& Schmitz, H. (1998). Trust and Inter-Firm Relations in Developing and Transition Economies. The Journal of Development Studies, 34(4), 32-61.

Islam, M. A., Wakai, S., Ishikawa, N., Chowdhury, A. M., \& Vaughan, J. P. (2002). Costeffectiveness of community health workers in tuberculosis control in Bangladesh. Bulletin of the World Health Organization, 80(6), 445-450.

Kahn, J. G., Yang, J. S., \& Kahn, J. S. (2010). 'Mobile' Health Needs and Opportunities In Developing Countries. Health Affairs, 29(2), 252-258.

Kaonga, N. N., Labrique, A., Mechael, P., Akosah, E., Ohemeng-Dapaah, S., Baah, J. S., \& Levine, O. (2013). Using Social Networking to Understand Social Networks: Analysis of a Mobile Phone Closed User Group Used by a Ghanaian Health Team. Journal of Medical Internet Research, 15(4).

Kimaro, H. C., \& Nhampossa, J. L. (2005). Analyzing the problem of unsustainable health information systems in less-developed economies: Case studies from Tanzania and Mozambique. Information Technology for Development, 11(3), 273-298.

Kobetz, E., Menard, J., Diem, J., Barton, B., Blanco, J., Pierre, L., \& Brewster, C. (2009). Community-Based Participatory Research in Little Haiti: Challenges and Lessons Learned. Process in Community Health Partnerships: Research, Education, and Action, 3(2), 133-137. 
Larsen-Cooper, E., Bancroft, E., Rajagopal, S., O'Toole, M., \& Levin, A. (2016). Scale Matters: A Cost-Outcome Analysis of an $\mathrm{m}$-Health Intervention in Malawi. Telemedicine and $e-$ Health, 22(4), 317-324.

Lehmann, U., \& Sanders, D. (2007). Community health workers: What do we know about them? Geneva: World Health Organization.

Lewin, S. A., Babigumira, S. M., Bosch-Capblanch, X., Aja, G., van Wyk, B., Glenton, C., \& Daniels, K. (2006). Lay health workers in primary and community health care: A systematic review of trials.

Liu, A., Sullivan, S., Khan, M., Sachs, S., \& Singh, P. (2011). Community Health Workers in Global Health: Scale and Scalability. Mount Sinai Journal of Medicine, 78, 419-435.

Macintyre, K., Lochigan, M., \& Letipila, F. (2003). Understanding referral from primary care clinics in rural Kenya: using health information systems to prioritize health services. The International Journal of Health Planning and Management, 18(1), 23-39.

Mitsunaga, T. M. (2014). Assessing data quality in the community health worker (CHW) program in Eastern province, Rwanda.

Naicker, S., Plange-Rhule, J., Tutt, R. C., \& Eastwood, J. B. (2009). Shortage of Healthcare Workers in Developing Countries - Africa. Ethnicity and Disease, 19, 60-64.

Narteh, B., \& Kuada, J. E. (2014). Customer satisfaction with retail banking services in Ghana. Thunderbird International Business Review, 56(4), 353-371.

Nichter, M. (1984). Project community diagnosis: Participatory research as a first step toward community involvement in primary health care. Social Science and Medicine, 19(3), $237-252$.

Odhiambo-Otieno, G. W., \& Odero, W. W. (2005). Evaluation criteria for the district health management information systems: lessons from the Ministry of Health, Kenya. African Health Services, 5(1), 59-64.

Omumbo, J., Ouma, J., Rapuoda, B., Craig, M. H., le Sueur, D., \& Snow, R. W. (1998). Mapping malaria transmission intensity using geographical information systems GIS: an example from Kenya. Annals of Tropical Medicine and Parasitology, 92(1), 7-21.

Patton, M. Q. (2002). Qualitative Research and Evaluation Methods. Sage Publications, Inc.

Peters, D. H., Garg, A., Bloom, G., Walker, D. G., Brieger, W. R., \& Raham, M. H. (2008). Poverty and Access to Health Care in Developing Countries. Annals of the New York Academy of Sciences, 161-171.

Portes, A. (1998). Social Capital: Its Origins and Applications in Modern Sociology. Annual Reviw of Sociology, 24(1), 1-24.

Prasad, S. (2015). Designing for Scalability and Trustworthiness in mHealth Systems. In Distributed Computing and Internet Technology (pp. 114-133). Springer International Publishing.

Qin, R., Dzombak, R., Amin, R., \& Mehta, K. (2013). Reliability of a Telemedicine System Designed for Rural Kenya. Journal of Primary Care and Community Health, 4(3), 177-181.

Ronsmans, C., Bennish, M. L., \& Wierzba, T. (1988). Diagnosis and Management of Dysentery by Community Health Workers. The Lancet, 332(8610), 552-555.

Shovlin, A., Ghen, M., Simpson, P., \& Mehta, K. (2013). Challenges Facing Data Digitazation in Low-resource Contexts. IEEE 2013 Global Humanitarian Technology Conference. San Jose.

Stekelenburg, J., Kyanamina, S. S., \& Wolfers, I. (2003). Poor performance of community health workers in Kalabo District, Zambia. Health Policy, 65(2), 109-118. 
Strachan, D. L., Källander, K., ten Asbroek, A. H., Kirkwood, B., Meek, S. R., Benton, L., \& Hill, Z. (2012). Interventions to Improve Motivations and Retention of Community Health Workers Delivering Integrated Community Case Management (iCCM): Stakeholder Perceptions and Priorities. The American Jouranl of Tropical Medicine and Hygiene, 87(5), 111-119.

Swider, S. M. (2002). Outcome Effectiveness of Community Health Workers: An Integrative Literature Review. Public Health Nursing, 19(1), 11-20.

Swider, S. M. (2002). Outcome Effectiveness of Community Health Workers: An Integrative Literature Review. Public Health Nursing, 19(1), 11-20.

Trause, D., Peterson, S., Doty, N., Ligouri, A., Mehta, K., \& Kanzleiter, L. (n.d.). Movements in Community Primary Care: Exploring the Role of Community Health Workers in Rural Nyeri, Kenya.

Trause, D., Peterson, S., Doty, N., Liguori, A., Holmes, K., Kanzleiter, L., \& Mehta, K. (2014). The Diverse Roles of Community Health Workers: Cues for Technology Innovations. Humanitarian Technology: Science, Systems and Global Impact 2014.

Wenner, G., Marino, M., Obeysekare, E., \& Mehta, K. (2014). Making data collection in lowresource contexts intuitive, fun, and interactive. Global Humanitarian Technology Conference (GHTC) (pp. 49-56). San Jose: IEEE.

Witmer, A., Seifer, S. D., Finocchio, L., Leslie, J., \& O'Neil, E. H. (1995). Community Health Workers: Integral Members of the Health Care Work Force. American Journal of Public Health, 85(8), 1055-1058.

Woolcock, M., \& Narayan, D. (2000). Social Capital: Implications for Development Theory, Research, and Policy. The World Bank Research Observer, 15(2), 225-249.

World Health Organization. (2011). World Health Statistics 2011. Geneva: World Health Organization.

World Health Organization. (2014). World Health Statistics 2014. Geneva: World Health Organization. 